WP ECON 15.03

Valuation of Safety under ReferenceDependent Evaluation of Income

José Antonio Robles-Zurita (U. Pablo de Olavide)

JEL Classification numbers: I100; D610; D120

Keywords: Reference-dependent; relative income, willingness to pay, road safety, contingent valuation 


\section{Valuation of Safety under Reference-Dependent Evaluation of Income}

Dr. José Antonio Robles-Zurita

Pablo de Olavide University. Department of Economics, Quantitative Methods and Economic History, Ctra. de Utrera, km. 1,

41013, Seville. Spain. E-mail: jarobzur@upo.es. Phone: +34 954348913 


\section{Abstract}

We analyze data of a Spanish nationally-representative survey where subjects reported their Willingness To Pay (WTP) for road safety improvements; specifically they hypothetically paid for a reduction of the risk of a road fatality and several injuries. Respondents also reported their current income (CI) and permanent income (PI). The latter refers to their normal income once they considered various stages of low/high earnings throughout their entire lives. Consequently, we define relative income as the comparison of CI with respect to PI. Three income frames are generated as explanatory variables: Gain (with $\mathrm{CI}>\mathrm{PI}$ ); Neutral (with $\mathrm{CI}=\mathrm{PI}$ ); and Loss scenario (with $\mathrm{CI}<\mathrm{PI}$ ). Surprisingly, we find that conditional on current income, and on a set of characteristics, those respondents in gain frame reported higher WTP than those in neutral and loss scenario. Further analysis shows that the income frames effect is higher and more significant for the older half-sample ( $>45)$, being about three or four times higher than for the younger subset. Possible interpretations of the role of PI as a reference point are considered given the results. A reference-dependent utility function of income, where PI is the reference point, is proposed to describe the monetary valuation of safety within the theoretical framework previously developed in the safety economics literature.

Keywords: reference-dependent; relative income, willingness to pay, road safety, contingent valuation. 


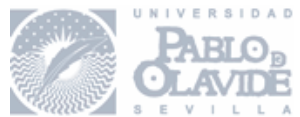

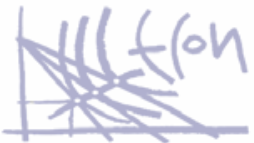

\section{INTRODUCTION}

Monetary valuation of safety improvements is crucial for the appraisal of (road) safety programs. Also, it is widely accepted that Willingness to Pay (WTP) for reduction of death and injury risks should be the grounds for the estimation of Value of Statistical Life (VSL) and Value of Preventing an Injury (VPI) (Andersson, 2013 and 2007; Blaeij et al., 2003). In this sense, one important aspect is the relationship between WTP and income because it justifies adjustment of economic values to new income situations between social groups and updating over time. For example, the UK Department for Transport updates the VSL and VPI indexed by GDP per head (see Spackman et al., 2011). In previous studies it has been estimated a significant positive relationship between income and WTP for safety improvements (Andersson, 2013 and 2007; Hammitt and Robinson, 2011; Lindhjem et al., 2011; Persson et al. 2001a; Jones-Lee et al. 1993 and 1985), implying that safety is a normal good.

The link between income and WTP has been predicted by theory in safety economics. Specifically it has been stated that the Marginal Rate of Substitution (MRS) of wealth for risk of death (or injury) for an expected utility maximizer increases with wealth (Jones-Lee, 1974, 1976 and 1989). Indeed this theoretical prediction is more general than what has been empirically found. Wealth is a broad concept that includes not only income but accumulated assets. Even more, income can be divided into current, past and future income. In this sense current, past and future income should affect WTP in the same manner because they are different components of wealth. However, previous studies only take into account current income (Andersson 2013 and 2007; Hammitt and Robinson, 2011; Lindhjem et al., 2011; Persson et al. 2001a; Jones-Lee et al. 1993 and 

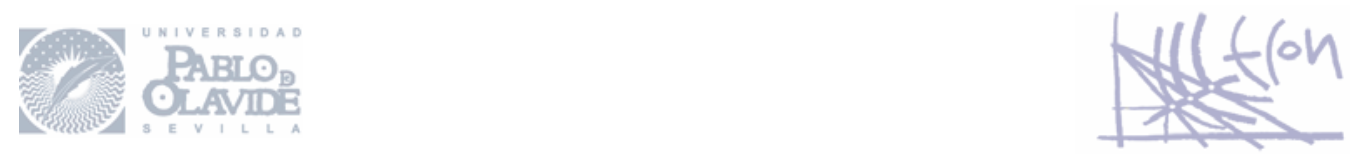

1985). So far different incomes throughout the economic life cycle have been ignored. Despite the fact that current income should be closely correlated with past and future income we can establish different situations in which they do not coincide. Consider the average or "normal level" of income throughout the entire life of an individual, also called permanent income. There are situations in which individuals are in a low or high income stage according to whether they are below or above their permanent income. Previous theoretical and empirical analyses of safety valuation do not differentiate between these situations. However an interesting question is whether people's WTP is affected by the stage of the economic life-cycle and what is the role of the permanent income (PI) in addition to current income (CI).

There is a growing literature indicating that the behavioral effect of PI (i.e. the average of past, current and future income) on people is different to the effect of CI as explained by Clark et al. (2008). They postulate that past and future income is a reference point (or reference income) in comparison to which a person evaluates current income. In this sense, utility is positively related to relative income, defined as the comparison of current income with respect to income in the past and future. As a consequence, utility increases with current income but decreases with past and (expected) future earnings. There is evidence from the subjective well-being literature supporting this idea. For example, it has been found that past income negatively affects job satisfaction (Clark, 1999; Grund and Sliwka, 2007). Also in McBride’s experiment (2010) subjects played matching pennies games against a computer such that the aspiration levels of earnings were manipulated and a negative correlation between this expectation and satisfaction at the end of the game was found. 
Even more, the evaluation of money with respect to a reference point is already present in one of the most prominent model of decision under risk, Prospect Theory (Kahneman and Tversky, 1979; and Tversky and Kahneman, 1992). It entails that risk preferences shift when lottery outcomes are framed as losses rather than as gains. People are in general risk averse in the gain domain and risk seekers in a loss scenario. Also individuals are specially risk averse when alternatives are mixed lotteries (i.e. lotteries with positive and negative outcomes). They account for these behavioral patterns by considering a value function with a varying shape for losses and gains. Specifically the value function of money has the properties of loss aversion and diminishing sensitivity to outcomes. Accordingly, we can consider that a person with current income above (below) past and future income is in a gain (loss) scenario. Therefore the shape of the utility function of income would vary in those two situations as suggested by Prospect Theory. ${ }^{1}$

In the present paper, we show that if a reference-dependent utility function is consider into a model of safety valuation previously used in the literature (see for example Carthy et al., 1998; or Jones-Lee, 1976) it is obtained that, given a constant level of CI, those people who are in a Gain frame (henceforth $\mathrm{G}$ ), with $\mathrm{CI}>\mathrm{PI}$, are willing to pay more for safety improvements than those in a Neutral (henceforth $\mathrm{N}$ ), with $\mathrm{CI}=\mathrm{PI}$, or Loss income frame (henceforth $\mathrm{L}$ ), with $\mathrm{CI}<\mathrm{PI}$. This reference-dependent utility function depends on both CI and PI, but the role of the latter is that of a reference point.

\footnotetext{
${ }^{1}$ The concept of value function is normally used in the context of Prospect Theory (Kahneman and Tversky, 1979; and Tversky and Kahneman, 1992). In the present context we will use the more traditional concept of utility function of income as in Safety Economics (see Carthy et al., 1998; or Jones-Lee, 1976). Both terms refer to the same idea of attaching a number to each amount of money in order to explain behavior.
} 


\section{Date}

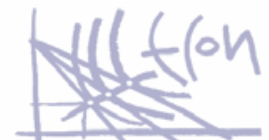

Also, it has the typical properties of loss aversion and diminishing sensitivity (Kahneman and Tversky, 1979; and Tversky and Kahneman, 1992).

In addition we analyze data from a Contingent Valuation (CV) study in Spain carried out to elicit the VSL and the VPI in the context of road safety. In the survey respondents were asked about their WTP for reducing the risk of death and several non-fatal injuries. They also reported their monthly current income and their monthly permanent income. We estimate a quantile regression with WTP as dependent variable, and income frames dummies, CI and socio-demographic characteristics as explanatory variables. In the first place, we find the same positive effect on WTP for CI as in previous studies. However, we find that WTP is higher for those subjects included in $G$ than for those in $N$ and $L$. Given that this effect is found after controlling for CI we have a negative relationship between wealth (generated in the past or future) and WTP. This result is opposite to previous theoretical predictions (Jones-Lee, 1974, 1976 and 1989) but consistent with the above mentioned reference dependent utility function. We also find that the effect of the income frames is higher and more statistically significant for the older group (those above 45) being about three or four times higher than for the younger subset. To the best of our knowledge the theoretical and empirical findings in this study are innovative and have never been exploited in the safety literature.

In the next section we present a reference-dependent utility function within the theoretical framework of valuation of safety. Then details about the CV study are exposed. Results are reported in section 4. Eventually section 5 contains a discussion and conclusion. 


\section{A REFERENCE DEPENDENT UTILITY FUNCTION}

In this section we follow the theoretical framework developed in Carthy et al. (1998) and Jones-Lee (1974 and 1976). It can be shown that under expected utility theory the theoretical MRSs of wealth for risk of death and injury, respectively, are given by the next expressions:

$$
\begin{aligned}
& m_{D}=\frac{\partial w}{\partial p}=\frac{U(w)-D(w)}{(1-p) U^{\prime}(w)+p D^{\prime}(w)} \\
& m_{I}=\frac{\partial w}{\partial q}=\frac{U(w)-I(w)}{(1-q) U^{\prime}(w)+q I^{\prime}(w)}
\end{aligned}
$$

Where the numerator is the difference between the utility of wealth conditional on normal health, $U(w)$, and the utility conditional on death, $D(w)$ (at expression 1), or the utility conditional on suffering an injury, $I(w)$ (expression 2). The denominator is a weighted average of the marginal utilities. The probability of having a fatal and nonfatal accident are $p$ and $q$ respectively.

Expressions (1) and (2) are very helpful because they allow us to study the relationship between the MRSs and wealth. It can be shown that $m_{D}$ (and $m_{I}$ ) increases with wealth as analyzed in Jones-Lee (1974 and 1976). Sufficient assumptions can be considered for this result to be true: a) Utility of wealth is increasing and marginal utility is decreasing with wealth, so $U^{\prime}(w)>0, U^{\prime \prime}(w)<0, \quad D^{\prime}(w)>0, D^{\prime \prime}(w)<0$ and $I^{\prime}(w)>$ $0, I^{\prime \prime}(w)<0$; b) Also, utility and marginal utility of wealth is higher conditional on 
good health than conditional on death or injury, so $U(w)>D(w), I(w)$ and $U^{\prime}(w)>$ $D^{\prime}(w), I^{\prime}(w)$.

Now the main modification we introduce into this model is the consideration of a different effect of current income and permanent income on the utility function. Consider that the utility conditional on normal health, $U(c i, r)$, depends on current income, $c i$, and on a reference point, $r$. Where $r$ is given by the permanent income. Utilities conditional on death and on injury depend only on current income: $D(c i)$ and $I(c i)$ respectively. ${ }^{2}$ In this setting, subjects are willing to trade current income for safety improvements. Therefore we can compute the theoretical MRS of $c i$ for risk of death or injury (see Appendix A):

$$
\begin{aligned}
& m_{D}(c i, r)=\frac{\partial c i}{\partial p}=\frac{U(c i, r)-D(c i)}{(1-p) U_{c i}(c i, r)+p D^{\prime}(c i)} \\
& m_{I}(c i, r)=\frac{\partial c i}{\partial q}=\frac{U(c i, r)-I(c i)}{(1-q) U_{c i}(c i, r)+q I^{\prime}(c i)}
\end{aligned}
$$

Here $m_{D}$ and $m_{I}$ are defined as a function of current income, $c i$, and the reference point, $r$. We have a representation of $U(c i, r)$ in Figure 1 . This function has the following properties:

Property 1. It is an increasing and decreasing function of $c i$ and $r$ respectively.

So that we have the following:

$$
\begin{aligned}
& \forall c i, U\left(c i, r_{1}\right) \lesseqgtr U\left(c i, r_{2}\right) \Leftrightarrow r_{2} \lesseqgtr r_{1} \\
& \forall r, U\left(c i_{1}, r\right) \lesseqgtr U\left(c i_{2}, r\right) \Leftrightarrow c i_{1} \lesseqgtr c i_{2}
\end{aligned}
$$

\footnotetext{
${ }^{2}$ We assume that the utility conditional on death and injury are not reference dependent for ease of exposition. However, the same theoretical results shown in this section can be derived in case that we consider $D($.$) and I($.$) to be affected by r$. In that case we just have to assume that the marginal effect of $r$ is higher conditional on normal health, i.e. $\left|U_{r}(c i, r)\right|>\left|D_{r}(c i, r)\right|,\left|I_{r}(c i, r)\right|$.
} 
Property 2. Loss aversion. That means that the marginal utility of current income is higher in the loss frame than in the gain frame. Formally:

$\lambda U_{c i}\left(c i_{1}, r\right)=U_{c i}\left(c i_{2}, r\right)$ whenever $c i_{1}>r>c i_{2}$ and $c i_{1}-r=r-c i_{2}$. With $\lambda>1$.

Property 3. Diminishing sensitivity. The utility function is concave for gains and convex for losses. This is the marginal utility of current income, $U_{c i}(c i, r)$, is decreasing w.r.t. $\mathrm{ci}$ for gains and increasing for losses. Given loss aversion, property 3 implies that the marginal utility is higher in the neutral frame (when $c i=r):^{3}$

$$
U_{c i}(c i, r)<U_{c i}(c i, c i) \text { whenever } r \lessgtr c i .
$$

Property 4. The marginal utility of current income is a function of the difference between current income and the reference point. Formally: $U_{c i}(c i, r)=$ $f(c i-r)$. This property is implicitly satisfied by the typical referencedependent function by assuming $U(c i, r)=g(c i-r)$, i.e. the utility of income is a function of gains/losses (for instance Tversky and Kahneman, 1992). ${ }^{4}$

\footnotetext{
${ }^{3}$ Notice that given the definition of property 2 (loss aversion) the utility function is not continuously differentiable at the neutral point $(c i=r)$ so that $U_{c i}(c i, c i)$ does not exist. However, we are only interested in the left partial derivative of current income at this point given that we are analyzing the change of utility given a reduction in current income (willingness to pay). Therefore it has to be interpreted that $U_{c i}(c i, c i)=\lim _{c i \rightarrow r^{-}} U_{c i}(c i, r)$.

${ }^{4}$ Notice that what is assumed by the typical reference dependent function is more restricted than property 4. For example, in case that current income and the reference point increase in the same amount (this is relative income remains constant) it would not have an impact on utility. However, property 4 allows for absolute income (increments of current income and reference point in the same quantity) to have an impact on utility.
} 
Assuming this properties we can show that MRS is higher for those in a Gain income frame than for those in a Neutral or Loss scenario. To do that we will make three further formal assumptions:

A1. We have $r_{G}, r_{N}$ and $r_{L}$ as the reference points of those in $G, N$ and $L$ respectively. By definition, permanent income in $G(L)$ is below (above) current income. Also PI equals $\mathrm{CI}$ in $N$. Formally, we assume that given a certain level of ci it happens that $r_{G}<r_{N}=c i<r_{L}$

A2. We will also assume $r_{G}-c i=c i-r_{L}$. This means that the distance between current income and the reference point (the permanent income) is the same for those in the Loss and Gain frame. ${ }^{5}$

A3. We will assume that the numerator and denominator in expressions (3) and (4) are positive because utility conditional on normal health is higher than conditional of death and injury, $U(c i)>D(c i), I(c i)$, and marginal utility is higher than zero, $U_{c i}(c i, r)>$ $0, D^{\prime}(c i)>0$, and $I^{\prime}(c i)>0$.

We have the next propositions:

Proposition 1 Those respondents in G pay more than those in L, conditional on having the same ci. This is $m_{D}\left(c i, r_{G}\right)>m_{D}\left(c i, r_{L}\right)$. Proof: Step 1. Given $A 1$ property 1 implies that $U\left(c i, r_{G}\right)>U\left(c i, r_{L}\right)$. Step 2. Given $A 2$, property 2 and property 4 we have $U_{c i}\left(c i, r_{G}\right)<U_{c i}\left(c i, r_{L}\right)$. To see this imagine $c i^{*}$ such that $c i-r_{G}=r_{G}-c i^{*}$ then by property $2 \lambda U_{c i}\left(c i, r_{G}\right)=U_{c i}\left(c i^{*}, r_{G}\right)$. Since we assume $A 2$ then we have $r_{L}-c i=r_{G}-c i^{*}$ and by property 4 we have

\footnotetext{
${ }^{5}$ We are able to explain the results also if the distance with the reference point is different for $L$ and $G$. However for ease of presentation we see better to make that assumption.
} 
$U_{c i}\left(c i, r_{L}\right)=U_{c i}\left(c i^{*}, r_{G}\right)$. Therefore $\lambda U_{c i}\left(c i, r_{G}\right)=U_{c i}\left(c i, r_{L}\right)$. By step 1 and 2 the numerator (denominator) in equation (5) is higher (lower) for those in G. Hence given A3 we have $m_{D}\left(c i, r_{G}\right)>m_{D}\left(c i, r_{L}\right)$

Proposition 2 Those respondents in G pay more than those in $N$, conditional on having the same ci. This is $m_{D}\left(c i, r_{G}\right)>m_{D}\left(c i, r_{N}\right)$. Proof: Step $1 . A 1$ and property 1 imply that $U\left(c i, r_{G}\right)>U\left(c i, r_{N}\right)$. Step 2 . Given $A 1$ and property 3 we know that $U_{c i}\left(c i, r_{G}\right)<U_{c i}\left(c i, r_{N}=c i\right)$. By step 1 and 2 the numerator (denominator) in equation (5) is higher (lower) for those in G. Hence given A3 we have $m_{D}\left(c i, r_{G}\right)>m_{D}\left(c i, r_{N}\right)$

As can be noticed, MRS is higher for those in the Gain frame because both the level of utility is higher and the marginal utility of current income is lower in that scenario given the properties of the utility function. Proceeding as in Propositions 1 and 2 we can prove that $m_{I}\left(c i, r_{G}\right)>m_{I}\left(c i, r_{L}\right)$ and $m_{I}\left(c i, r_{G}\right)>m_{I}\left(c i, r_{N}\right)$ just changing $m_{D}(.,$.$) for$ $m_{I}(.,$.$) .$ 


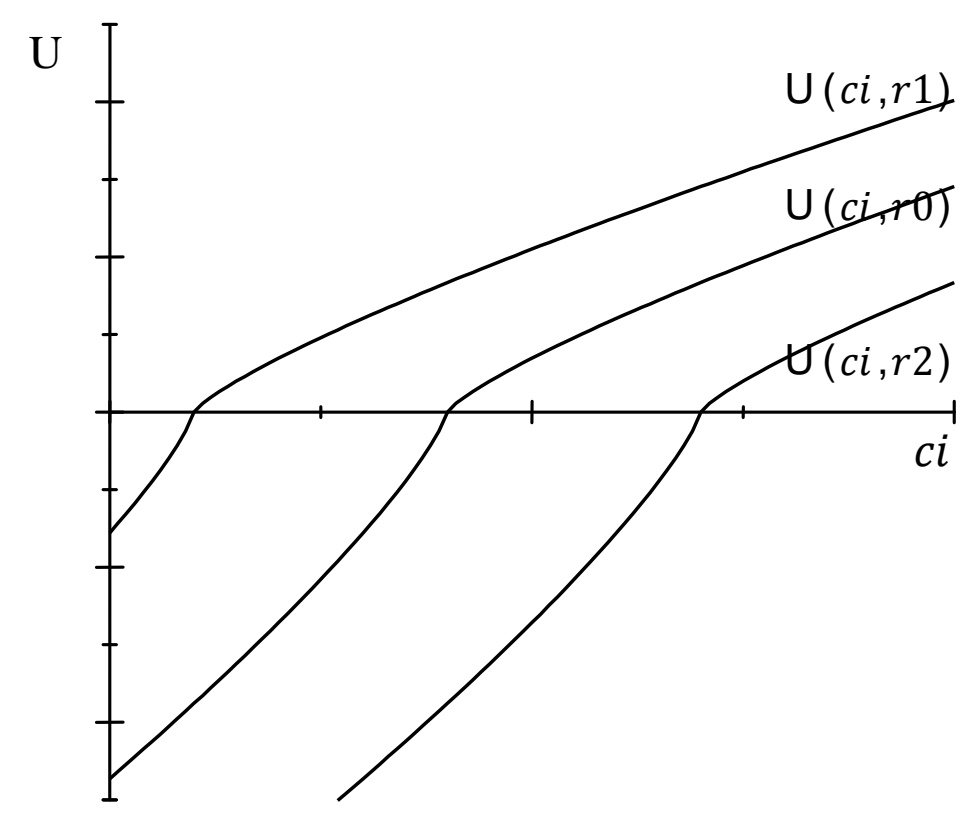

Figure 1. Reference-Dependent Utility Functions with $r 1<r 0<r 2$

\section{THE CONTINGENT VALUATION STUDY}

\subsection{The survey}

The Spanish Road Traffic Directorate General funded a CV survey consisted of Computer-Assisted Personal Interviews (CAPI) conducted from November 2010 to March 2011. ${ }^{6}$ A questionnaire was presented to 4,036 subjects. Here we analyze responses of 3,271 individuals that reported information about their income. All these subjects reported their WTP for reducing the risk of a road fatality (henceforth a fatality is represented by D). In addition, a subsample of 2,016 respondents reported their WTP for preventing some Non Fatal Road Injuries (NFRI, see Figure B1 in Appendix B for a

\footnotetext{
${ }^{6}$ Applications of the CV method to road safety valuation are Jones-Lee et al. (1985 and 1995), Carthy et al. (1998), Persson et al. (2001a and 2001b).
} 
description) $^{7}$ as in previous studies (see Jones-Lee et al., 1993; Robinson et al., 2001). Up to eight injuries varied with respect to: time in hospital, the extent and duration of pain, degree and length of restrictions to leisure and work activities, degree of physical and mental ability, and independency for basic physiological needs. So NFRIs extended over a wide range from the mildest ones, like $\mathrm{F}$ or $\mathrm{W}$, to the most serious ones, like $\mathrm{N}$ or L. In Table I it is shown the number of subjects that reported their WTP for preventing a fatality and each injury. ${ }^{8}$

Table I. Number of respondents valuing $D$ and each injury

\begin{tabular}{ccccccccc}
\hline \hline $\mathbf{D}$ & $\mathbf{F}$ & $\mathbf{W}$ & $\mathbf{X}$ & $\mathbf{V}$ & $\mathbf{S}$ & $\mathbf{R}$ & $\mathbf{N}$ & $\mathbf{L}$ \\
3,271 & 758 & 505 & 754 & 749 & 501 & 752 & 503 & 503
\end{tabular}

Note: D stands for a fatality, $\mathrm{F}$ to $\mathrm{L}$ are injuries described in Figure B 1 .

\subsection{WTP for safety improvements}

The CV method involved asking respondents about the amount of money they were willing to pay for reducing the risk of a traffic accident with fatal or non fatal consequences. For example, the formulated CV question for preventing a risk of death was:

\footnotetext{
${ }^{7}$ All the interviews were carried out in Spanish though in the present article it will be shown the English translation.

${ }^{8}$ Differences in specific NFRIs valued by each subject were random and due to other research objectives that do not affect the analysis presented here. Further information may be available for the reader upon request.
} 
Suppose your risk of death as a result of a traffic accident is 15 in 100,000 and that there exists a safety device that will reduce your risk of death in a traffic accident in 5 / 100,000, from 15 in 100,000 to 10 in 100,000. Would you be willing to pay ....

After the question was formulated different amounts of money in Euros were proposed to the respondent that rejected or accepted to pay. The indifference level she finally reported was between the highest amount of money that she was willing to pay and the lowest amount of money that she was not willing to pay. All the CV questions, for death and injury, had a risk reduction of 5 in 100,000 (0.00005). Several examples showed to respondents that a probability of $\mathrm{X}$ in 100,000 should be interpreted as $\mathrm{X}$ people having a (non)fatal accident form a pool of 100,000 people. Also they were told that the security device is for single use, works in all modes of transport, and has one year of duration.

Given CV responses, the interesting computation for policy purposes is the MRS of wealth/current income for risk of accident. Since the safety improvement assumed is sufficiently small we can compute the MRS as the ratio between the amount of money a respondent is willing to pay, $w t p_{D}$ and $w t p_{I}$, to the risk reduction considered:

$$
\begin{aligned}
& m_{D} \cong \frac{w t p_{D}}{\text { risk reduction }} \\
& m_{I} \cong \frac{w t p_{I}}{\text { risk reduction }} .
\end{aligned}
$$

\subsection{Measurement of current and permanent income: the income frames}

Two different questions were included to measure current income and permanent income. The first refers to the amount of money earned at the present moment, while the 
latter has to do with a long term concept of income like the average earnings throughout a whole life.

First respondents were asked about their CI as follows:

...Regarding the level of your monthly household income, and approximately, could you mark the interval that correspond to your situation?

a) Less than $€ 600$.

b) Between $€ 601$ and $€ 900$.

c) Between $€ 901$ and $€ 1,200$.

d) Between $€ 1,201$ and $€ 1,800$.

e) Between $€ 1,800$ and $€ 2,500$.

f) Between $€ 2,501$ and $€ 3,500$.

g) Between $€ 3,501$ and $€ 5,000$.

h) More than $€ 5,000$.

Then they were asked about their PI as:

...As you may know, over the life of an individual different stages in terms of income occur (sometimes you earn a lot, others less). When we consider these various stages, we people are able to identify a "normal income level" throughout our entire lives. This results in that you may think that your current income level is above or below its "normal income level." What would be, among the following, your "normal income level"? 9

\footnotetext{
${ }^{9}$ Respondents were said to report their "normal income level throughout their entire lives". So they had to consider past, current and future income. In the case of the future they were supposed to have made a prediction. In this regard their PI was subject to some uncertainty.
} 
a) Less than $€ 600$.

b) $\ldots$

In Table II it is shown the distribution of the sample according to CI, PI and the income frames. There is a tendency for the reported CI to be lower than the PI. For example, the median CI is between $€ 900$ and $€ 1,200$ while the median PI is in the interval $€ 1,200$ $€ 1,800$. This is also observed in the income frames. The majority, 1,980 subjects (60.5\%), reported to be in a neutral position $(N)$. The second most frequent frame is Loss, 1,052 respondents (32.1\%). Eventually, 239 subjects (7.3\%) are in Gains. This asymmetry in the distribution of frames is presumably due to the economic crisis that began in 2008 (three years before the survey was carried out).

\section{Table II. Percentage distribution of respondents according to income}

\begin{tabular}{lllll}
\hline \hline & & & \\
Income interval $(€)$ & $\mathrm{CI}$ & $\mathrm{PI}$ & Income frames \\
& & & & \\
$<=600$ & 9.7 & 5.4 & $\mathrm{~L}(\mathrm{CI}<\mathrm{PI})$ & 32.1 \\
$601-900$ & 15.7 & 12.6 & $\mathrm{~N}(\mathrm{CI}=\mathrm{PI})$ & 60.5 \\
$901-1,200$ & 24.6 & 20.0 & $\mathrm{G}(\mathrm{CI}>\mathrm{PI})$ & 7.3 \\
$1,201-1,800$ & 24.8 & 28.6 & & \\
$1,801-2,500$ & 15.8 & 20.1 & & \\
$2,501-3,500$ & 6.4 & 8.5 & & \\
$3,501-5,000$ & 2.1 & 3.7 & & \\
$>=5,001$ & 0.4 & 0.8 & & \\
\hline \hline
\end{tabular}

\subsection{Sample characteristics}

In Table III we see the distribution of some characteristics of the sample. To have an idea of the representativeness it is shown the distribution of gender and age according to 


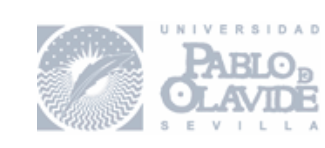

the 2011 Spanish Census of Population. The sample distribution of these variables is very similar to the population. For example, the sample is divided in two halves according to gender. The mean and median ages are 46 and 44 respectively. With respect to education, work status and marital status the sample is compared with the $1^{\text {st }}$ quarter of 2011 Spanish Labor Force Survey (LFS; see Instituto Nacional de Estadística, 2011). Almost half of the sample has primary education and only $24.2 \%$ tertiary education. The distribution for the LFS is very similar although there seems to be a higher proportion of Upper Secondary education in the sample. With respect to work status almost half of the sample, $48.6 \%$, is employed and $12.2 \%$ is unemployed. This yields a labor force participation rate of $60.8 \%$, a figure very similar to the $59.8 \%$ given by the LFS. Finally, most of the respondents are married followed by single subjects as in the LFS. Other characteristics that are considered in the analysis are Self Reported Health and whether respondents belong to a household with dependent elderly or minor children. Also accident experience refers to whether the respondent or her close people (husband/wife, parents, children and friends) have suffered a road accident. Subjects reported the distance in road travel during a year; the median is 5,000 kilometers. Finally, subjects are also divided according to whether they smoke, consume alcohol, do some physical activity and play gambling games with some frequency.

Table III. Percentage distribution of sample characteristics 


\begin{tabular}{|c|c|c|c|c|}
\hline \multirow[t]{2}{*}{ Gender and Age } & \multicolumn{4}{|c|}{ Dependent elderly at home } \\
\hline & Sample & Census (2011) & Yes & 92 \\
\hline Male & 49.6 & 49.3 & No & 8 \\
\hline \multirow[t]{2}{*}{ Female } & 50.3 & 50.6 & & \\
\hline & & & Minor children at home & \\
\hline $18-29$ & 17.76 & 16.1 & Yes & 34.7 \\
\hline 30-39 & 20.34 & 20.2 & No & 65.3 \\
\hline $40-49$ & 20.73 & 19.4 & & \\
\hline $50-65$ & 23.71 & 23.3 & Accident experience & \\
\hline \multirow[t]{2}{*}{$>=66$} & 17.46 & 20.9 & Yes & 39.4 \\
\hline & & & No & 60.6 \\
\hline \multicolumn{5}{|c|}{ Education, work and marital status } \\
\hline & Sample & LFS ( $1^{\mathrm{ST}}$ quarter 2011) & Kilometers a year & \\
\hline Primary and Lower Sec. & 47.8 & 54.8 & $<=5,000$ & 47.8 \\
\hline Upper Secondary & 27.9 & 20.3 & $>5,000$ & 52.2 \\
\hline \multirow[t]{2}{*}{ Tertiary } & 24.2 & 24.8 & & \\
\hline & & & Smoker & \\
\hline Employed & 48.6 & 47.1 & Yes & 35.7 \\
\hline Unemployed & 12.2 & 12.7 & No & 64.3 \\
\hline \multirow[t]{2}{*}{ Inactive } & 39.2 & 40.1 & & \\
\hline & & & Alcohol & \\
\hline Single & 25.3 & 31.4 & Yes & 59.7 \\
\hline Married & 61.4 & 56.5 & No & 40.3 \\
\hline Divorced & 6.5 & 4.8 & & \\
\hline \multirow[t]{2}{*}{ Widow } & 6.7 & 7.3 & Physical activity & \\
\hline & & & Yes & 59 \\
\hline Self Reported Health & & & No & 41 \\
\hline Excellent & 12.6 & & & \\
\hline Very good & 33.3 & & Gambling games & \\
\hline Good & 39.5 & & Yes & 23.5 \\
\hline Moderate or bad & 14.6 & & No & 76.5 \\
\hline
\end{tabular}

4. RESULTS 
In Figure 2 we see unconditional median WTP for the prevention of a risk of road fatality and injury by income frames. ${ }^{10}$ Interestingly, the pattern that we find is that those individuals in a Gain frame are willing to pay more than those in a Neutral or Loss frame. This happens for both preventing a risk of road fatality and injury (wilcoxon ranksum test $\mathrm{p}$-value $<0.01){ }^{11}$

In Table IV it is shown the results of the median estimation of WTP responses for preventing a risk of death and injury. The quantile regressions estimate the effect of the income frames after controlling for current income and the characteristics summarized in Table III. In the constant of the model we have a subject that is 18-years-old, female, in a Gain frame, with current income below 600€, with excellent health, married, with no elderly or children at home, primary education, permanent employee in the private sector, has no accident experience, travels less than 5,000 km of road a year, does not smoke, does not consume alcohol, does not do any physical activity, and does not play gambling games.

With respect to preventing a road fatality, estimated coefficients for the income frames are negative and significant, implying again that those in $N$ and $L$ are willing to pay less than those in G. Also, WTP is positively related to CI since we find the CI dummies to be highly significant, consistent with other studies (Andersson 2013 and 2007; Hammitt and Robinson, 2011; Lindhjem et al., 2011; Persson et al. 2001a; Jones-Lee et al. 1993 and 1985). With respect to the remaining significant variables: WTP is negatively affected by age, health and smoking, and; WTP increases with education, accident

\footnotetext{
${ }^{10}$ We report on the median CV responses because mean figures are extremely sensitive to the removal of some outliers.

${ }^{11}$ It can be seen that median WTP for preventing a risk of injury is slightly more than half of WTP for preventing a fatality. In order to interpret this figure we have to take into account that respondents reported WTP for avoiding consequences with varying degree of severity, including very serious conditions like $\mathrm{N}$ and L (see Table I above and Figure B1 in appendix).
} 

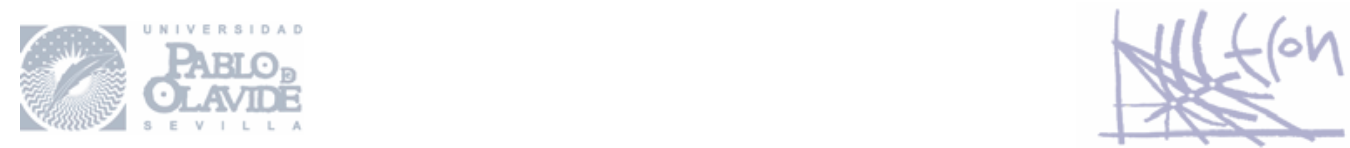

experience, road kilometers, physical activity and playing gambling games. The rest of the respondents' characteristics are not statistically significant. For the case of WTP for preventing an injury the results are the same with respect to the income frames (significant negative effect) and current income (significant positive effect). The rest of the characteristics are less significant. Nonetheless, it is found a significant positive coefficient for elderly at home, those retired, those who consume alcohol, who do some physical activity and who play gambling games.

Three comments can be said given the results. First it is surprising that conditional on current income those with a lower permanent income (those in $G$ ) are willing to pay more than those with a higher permanent income (those in $L$ and $G$ ) as predicted in section 2. This means that, after controlling for current income, we do find a negative effect of wealth on WTP, hence contradicting previous theoretical results (Jones-Lee, 1974, 1976 and 1989). Secondly, there are predicted situations in which subjects would be willing to pay more even when they have a lower current income, just because they are in a high earning stage within their life cycle. Specifically, quantile regression of WTP for preventing a risk of a fatality in Table IV predicts that those in G with a current income $€ 1,200-€ 1,800$ are willing to pay more than those in $\mathrm{L}$ or $\mathrm{N}$ with a current income $€ 1,800-€ 2,500$ and approximately the same than those with a current income $€ 2,500-€ 3,500$. Finally, the effect of the income frames is quantitatively important if compared with the median WTP for the whole sample. For example, the coefficient for $\mathrm{N}$ is $41.05 \%$ and $85.9 \%$ of the median WTP for preventing a risk of death and injury respectively (€78/€190 and €85.9/€100 respectively).

In Table $\mathrm{V}$ the interaction between the income frames effect and age is analyzed. First we divide the sample into two groups according to the median age, 45 years old. The 
same median quantile regressions previously shown in Table IV are estimated separately for the two age subgroups. Interestingly it is estimated that the coefficients of the Neutral and Loss income frames in the case of the older subsample (Age $>45$ ) are more significant and about 3 or 4 times higher than in the case of the younger subjects (Age $\leq 45$ ). This result holds for WTP for preventing a risk of both, death and injury. Secondly, to further test for the interaction between the income frames effect and age we estimate the same quantile regressions of Table $\mathrm{V}$ for the whole sample (All) and including interaction factors generated by multiplying the income frames variables by age: Neutral $\times$ Age and Loss $\times$ Age. For the case of WTP for preventing a risk of death the estimated coefficients are negative and significant implying that the effect of the income frames is more negative for older respondents. For instance, the negative effect of the Neutral group is estimated to increase by 35.6 Euros every 10 years. Similar negative coefficients are estimated for WTP for preventing an injury, however the significativity is lower ( $p$-values are 0.12 and 0.16 for Neutral $\times$ Age and Loss $\times$ Age respectively).

Therefore data shows that the effect of the income frames is clearly stronger for old subjects. Even more if we look at the All models in Table V it is noticed that the income frames effect is very small and clearly not significant for the youngest group, i.e. those 18-years-old respondents (see coefficients of the Neutral and Loss dummies). The interaction between income frames and age also affects the coefficient for Age. This coefficient reverses sign from negative, models for Age $\leq 45$ and Age $>45$, to positive, models for All. This suggests that Age reflects the negative effect of the interaction with income frames when the interaction factor is not properly included. 
The higher WTP for those subjects in a Gain income scenario can be explained by the reference dependent function proposed here in section 2 . This function is in line with the idea that the reference income could be either past or expected future income (backward or forward-looking) as proposed by Clark et al. (2008) in their section 2.2. However, the interaction that we find between the effect of the income frames and age could shed some light in the interpretation of permanent income as a reference point. Specifically, we have that the effect is stronger and more significant for old subjects than for young people. Given that the permanent income for the former group is mainly formed by past income a straight forward interpretation is that past income is the actual reference point but not future income. Also an alternative interpretation is that for young people their permanent income is subject to more uncertainty. Past income is something that already happened, therefore there is no uncertainty in their determination, but future earnings (the main component of permanent income for the youngest) are just expectations not known in advance. Then the reference point could be less important for young people because it is not certain.

Despite the fact that in this paper we rely on the idea of reference dependent evaluation of income, there could be other explanations for the findings. Specifically, those who are in a Gain frame could have different characteristics that could affect safety valuation. For example, the probability of being in Gain sharply declines for those above the age 65 (retirement age in Spain). ${ }^{12}$ Also preferences for safety changes with age as predicted by theory (Andersson, 2007). In our analysis we are able to control for

\footnotetext{
${ }^{12}$ In our study the percentage of people in Gain scenario for subjects aged $\leq 65$ is $8,16 \%$. While for those aged $>65$ is just $3,18 \%$.
} 


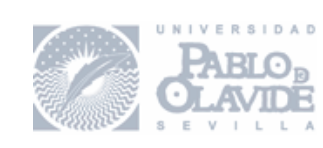

the effect of age and a variety of socio-demographic variables available in our dataset. ${ }^{13}$ However, we cannot control for unobserved heterogeneity. Past consumption is one unobserved variable plausibly correlated with the income frames. Probably those who are in a Loss frame consumed more in the past. If this consumption level cannot be changed in the present moment then they will have less disposable income to spend on safety. ${ }^{14}$ So it may be possible that differences between income frames are not driven by varying preferences but by liquidity restrictions. Also income at the present could be affected by ability to save money in the past, those subjects who had a low propensity to consume could generate more income from savings. Variation in valuation of safety could be driven by other characteristics correlated with propensity to save and not only by varying income level itself. ${ }^{15}$

\footnotetext{
${ }^{13}$ We also have estimated models in Table 4 including the more general specification of age (a dummy for each age year). The significativity and importance of the income frames do not change.

${ }^{14}$ Imagine, for example, that a person in Loss scenario bought an expensive house in the past. That kind of consumption is difficult to change even in the present situation of low earnings because usually it is linked to a loan or mortgage and it takes time to sell a house and buy a cheaper one.

${ }^{15}$ We believe that differences in propensity to save is not a huge problem for several reasons. First, savings income was about $9.12 \%$ of total household income in fiscal year 2011 according to the Annual Reports on Tax Collection in Spain (see Agencia Tributaria, 2014). Secondly, respondents reported income through wide intervals (see section 3.3 above) so that small variations in income should not have an impact on this categorical response. And third, it is likely that savings income affects both current and permanent income, so it is not clear whether the reported income frames are affected by propensity to save.
} 
Fatality

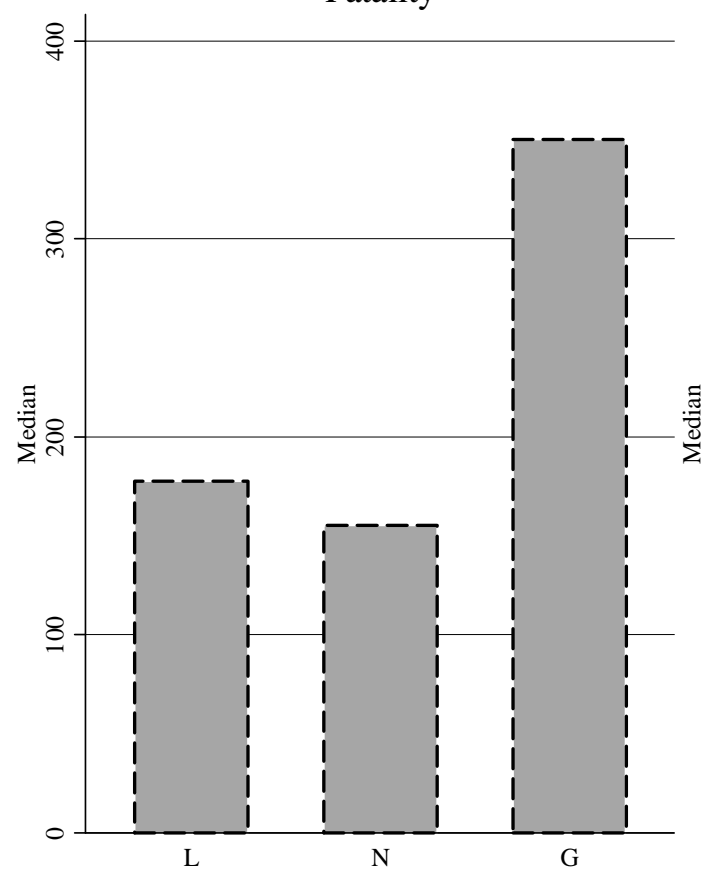

Injury

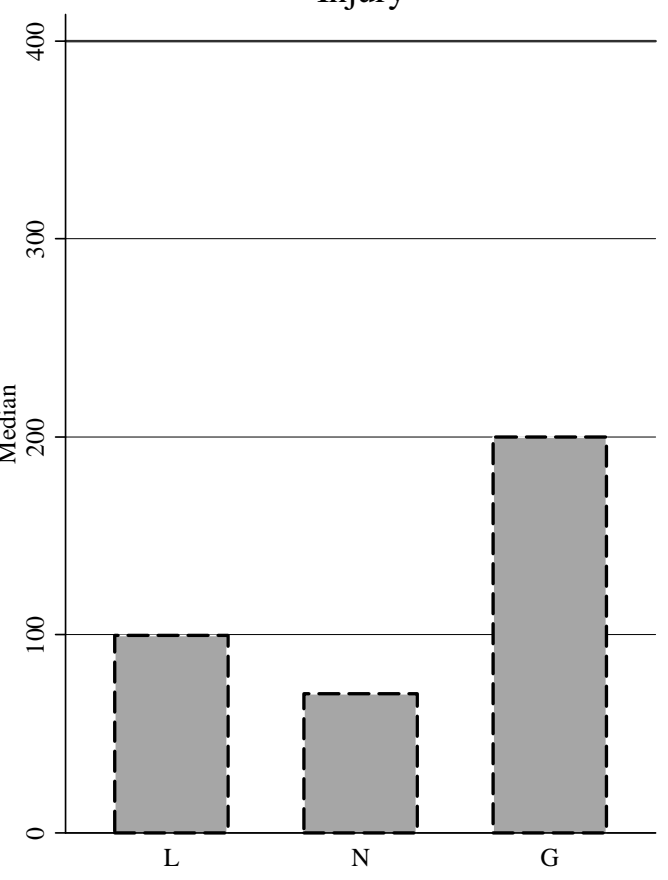

Figure 2. Median WTP (€) for preventing a risk of death and injury in different

frames: Loss (L), Neutral (N) and Gain (G).

Table IV. Median estimation of WTP (€)

\begin{tabular}{|c|c|c|c|c|c|}
\hline Explanatory variables & Fatality & Injury & Explanatory variables & Fatality & Injury \\
\hline Income frames & & & Education (Cons: primary) & & \\
\hline (Cons: Gain) & & & & & \\
\hline Neutral & $\begin{array}{l}-78.0 * * * \\
(25.7)\end{array}$ & $\begin{array}{l}-85.9 * \\
(45.2)\end{array}$ & Secondary & $\begin{array}{l}15.9 \\
(16.6)\end{array}$ & $\begin{array}{l}10.4 \\
(10.3)\end{array}$ \\
\hline Loss & $\begin{array}{l}-58.3^{* *} \\
(27.6)\end{array}$ & $\begin{array}{l}-83.4^{*} \\
(45.5)\end{array}$ & Vocational & $\begin{array}{l}137.2 * * * \\
(24.6)\end{array}$ & $\begin{array}{l}46.3 \\
(30.2)\end{array}$ \\
\hline$\frac{\text { Current Income }}{(€, \text { cons: }<=600)}$ & & & Tertiary & $56.1^{* * *}$ & 15.5 \\
\hline $601-900$ & $\begin{array}{l}32.0 \\
(25.5)\end{array}$ & $\begin{array}{l}18.9 * \\
(9.8)\end{array}$ & $\begin{array}{l}\text { Work status } \\
\text { (Cons: permanent employee-private sector) }\end{array}$ & $(21.4)$ & $(13.7)$ \\
\hline $901-1,200$ & $\begin{array}{l}68.6 * * * \\
(24.5)\end{array}$ & $\begin{array}{l}34.1 * * * \\
(11.2)\end{array}$ & Temp. Employee-private sector & $\begin{array}{l}-13.3 \\
(22.8)\end{array}$ & $\begin{array}{l}23.1 \\
(17.1)\end{array}$ \\
\hline $1,201-1,800$ & $\begin{array}{l}93.9 * * * \\
(26.0)\end{array}$ & $\begin{array}{l}35.9 * * * \\
(11.7)\end{array}$ & Perm. Employee-pub. sector & $\begin{array}{l}-54.1 \\
(33.1)\end{array}$ & $\begin{array}{l}-21.6 \\
(21.9)\end{array}$ \\
\hline $1,801-2,500$ & $\begin{array}{l}117.5^{* * *} \\
(29.2)\end{array}$ & $\begin{array}{l}43.8^{* * *} \\
(16.6)\end{array}$ & Temp. Employee-pub. sector & $\begin{array}{l}-53.4 \\
(50.0)\end{array}$ & $\begin{array}{l}-22.6 \\
(24.0)\end{array}$ \\
\hline $2,501-3,500$ & $\begin{array}{l}141.3^{* * *} \\
(35.8)\end{array}$ & $\begin{array}{l}41.5 \\
(29.0)\end{array}$ & Self-employed & $\begin{array}{l}-34.4 \\
(24.9)\end{array}$ & $\begin{array}{l}8.9 \\
(17.0)\end{array}$ \\
\hline $3,501-5,000$ & $\begin{array}{l}320.9 * * * \\
(50.3)\end{array}$ & $\begin{array}{l}170.6^{*} \\
(90.8)\end{array}$ & Unemployed & $\begin{array}{l}2.9 \\
(23.0)\end{array}$ & $\begin{array}{l}2.3 \\
(13.2)\end{array}$ \\
\hline$>5,000$ & $1,243.2^{* * *}$ & $469.2 * * *$ & Retired & 34.7 & $24.4^{*}$ \\
\hline
\end{tabular}




\begin{tabular}{|c|c|c|c|c|c|}
\hline & $(91.4)$ & $(143.8)$ & & $(26.0)$ & $(14.7)$ \\
\hline & & & Housewife & 2.9 & 10.3 \\
\hline \multirow{2}{*}{ Age } & $-17.9 * * *$ & -4.8 & & (25.1) & (12.8) \\
\hline & (6.5) & (3.3) & Student & 33.1 & 27.6 \\
\hline \multirow[t]{2}{*}{ Male } & -0.9 & -0.9 & & (36.3) & $(31.1)$ \\
\hline & $(14.4)$ & $(8.2)$ & Other & -38.4 & -16.3 \\
\hline \multicolumn{4}{|l|}{ Health (Cons: excellent) } & $(50.6)$ & (33.3) \\
\hline Very good & $\begin{array}{l}10.7 \\
(20.6)\end{array}$ & $\begin{array}{l}0.5 \\
(12.2)\end{array}$ & Accident experience & $\begin{array}{l}23.6^{*} \\
(13.2)\end{array}$ & $\begin{array}{l}-7.4 \\
(7.5)\end{array}$ \\
\hline Good & $\begin{array}{l}49.3^{* *} \\
(21.1)\end{array}$ & $\begin{array}{l}3.6 \\
(12.7)\end{array}$ & $>5,000 \mathrm{~km}$ a year & $\begin{array}{l}27.0^{*} \\
(14.2)\end{array}$ & $\begin{array}{l}4.4 \\
(8.1)\end{array}$ \\
\hline Moderate or Bad & $\begin{array}{l}54.8 * * \\
(26.4)\end{array}$ & $\begin{array}{l}5.8 \\
(13.8)\end{array}$ & Smoker & $\begin{array}{l}-37.6^{* * *} \\
(13.9)\end{array}$ & $\begin{array}{l}7.9 \\
(8.8)\end{array}$ \\
\hline $\begin{array}{l}\text { Marital status (Cons: } \\
\text { married) }\end{array}$ & & & Consumes alcohol & 13.4 & $19.6^{* *}$ \\
\hline \multirow[t]{2}{*}{ Single } & -5.7 & 2.4 & & $(14.0)$ & $(8.5)$ \\
\hline & $(19.7)$ & $(11.1)$ & Physical activity & $21.9 *$ & $13.5^{*}$ \\
\hline \multirow[t]{2}{*}{ Divorced } & 8.7 & 11.9 & & $(13.1)$ & $(8.0)$ \\
\hline & $(26.1)$ & $(24.6)$ & Plays gambling games & $76.9 * * *$ & $17.0 *$ \\
\hline Widow & $\begin{array}{l}-6.0 \\
(28.3)\end{array}$ & $\begin{array}{l}12.3 \\
(11.6)\end{array}$ & & $(15.0)$ & $(9.1)$ \\
\hline Elderly at home & $\begin{array}{l}33.7 \\
(22.8)\end{array}$ & $\begin{array}{l}27.3^{* *} \\
(13.2)\end{array}$ & Constant & $\begin{array}{l}144.5^{* * *} \\
(49.6)\end{array}$ & $\begin{array}{l}184.6^{* * *} \\
(51.1)\end{array}$ \\
\hline \multirow[t]{2}{*}{ Children at home } & -12.5 & -0.0 & Observations & 3,271 & 5,025 \\
\hline & $(15.7)$ & $(9.3)$ & Subjects & 3,271 & 2,016 \\
\hline
\end{tabular}

Note 1. These estimations are also controlling for month of the survey implementation and, in the case of WTP for prevention of injury, dummies indicating type of injury are included (see Figure B1 for type of injuries). Note 2. Estimated coefficients are above Standard Errors, the latter shown in brackets. Note 3. For the Injury estimation standard errors are clustered at subject level using bootstrap techniques. Note 4 . $* * *, * *$, and $*$ mean coefficient is significant at $1 \%, 5 \%$ and $10 \%$ of error respectively. Note 5 . Variable Age is a transformation of original age reported as $($ age -18$) \times 10$ so that 18-years-old subjects are in the constant in the model and coefficients are the differential effect for those 10 years older.

Table V. Median estimation of WTP (€) by age subgroups

\begin{tabular}{|c|c|c|c|c|c|c|}
\hline \multirow[b]{2}{*}{ Explanatory variables } & \multicolumn{3}{|c|}{ Fatality } & \multicolumn{3}{|c|}{ Injury } \\
\hline & Age $>45$ & Age $\leq 45$ & All & Age $>45$ & Age $\leq 45$ & All \\
\hline \multicolumn{7}{|l|}{ Income frames } \\
\hline \multicolumn{7}{|l|}{ (Cons: Gain) } \\
\hline Neutral & $\begin{array}{l}-219.7^{* * * *} \\
(42.8)\end{array}$ & $\begin{array}{l}-61.0 * \\
(34.5)\end{array}$ & $\begin{array}{l}-5.2 \\
(38.1)\end{array}$ & $\begin{array}{l}-191.9 * * * \\
(72.4)\end{array}$ & $\begin{array}{l}-44.9 \\
(42.6)\end{array}$ & $\begin{array}{l}-7.3 \\
(66.8)\end{array}$ \\
\hline Loss & $\begin{array}{l}-175.6^{* * *} \\
(45.0)\end{array}$ & $\begin{array}{l}-60.5 \\
(37.4)\end{array}$ & $\begin{array}{l}-2.4 \\
(40.8)\end{array}$ & $\begin{array}{l}-173.5^{* *} \\
(74.0)\end{array}$ & $\begin{array}{l}-58.2 \\
(43.9)\end{array}$ & $\begin{array}{l}-14.7 \\
(67.3)\end{array}$ \\
\hline Neutral $\times$ Age & & & $\begin{array}{l}-35.6^{* * * *} \\
(13.2)\end{array}$ & & & $\begin{array}{l}-39.7 \\
(25.7)\end{array}$ \\
\hline Loss $\times A g e$ & & & $\begin{array}{l}-30.6^{* *} \\
(13.8)\end{array}$ & & & $\begin{array}{l}-36.4 \\
(25.8)\end{array}$ \\
\hline Age & $-23.8^{*}$ & -23.4 & 15.1 & -5.7 & -13.5 & 33.3 \\
\hline
\end{tabular}




\begin{tabular}{|c|c|c|c|c|c|c|}
\hline & (13.1) & $(16.2)$ & $(13.4)$ & $(6.8)$ & $(10.7)$ & $(25.7)$ \\
\hline Constant & $\begin{array}{l}287.4^{* * *} \\
(93.7)\end{array}$ & $\begin{array}{l}156.2^{* *} \\
(70.8)\end{array}$ & $\begin{array}{l}76.5 \\
(51.2)\end{array}$ & $\begin{array}{l}240.5^{* * *} \\
(87.7)\end{array}$ & $\begin{array}{l}199.0^{* * *} \\
(60.1)\end{array}$ & $\begin{array}{l}114.4 \\
(69.9)\end{array}$ \\
\hline Observations & 1,606 & 1,665 & 3,271 & 2,524 & 2,501 & 5,025 \\
\hline Subjects & 1,606 & 1,665 & 3,271 & 1,007 & 1,009 & 2,016 \\
\hline
\end{tabular}

Note 1. These estimations are also controlling for the same variables included in Table 4. Note 2. Estimated coefficients are above Standard Errors, the latter shown in brackets. Note 3. For the Injury estimation standard errors are clustered at subject level using bootstrap techniques. Note 4. ***, **, and * mean coefficient is significant at $1 \%, 5 \%$ and $10 \%$ of error respectively. Note 5 . Variable Age is a transformation of original reported age as $(a g e-18) \times 10$ so that 18 -years-old subjects are in the constant of the model and coefficients are the differential effect for those 10 years older.

\section{DISCUSSION AND CONCLUSION}

The present analysis suggests that we can make more precise predictions of monetary valuation of safety by considering permanent income, in addition to current earnings. At the individual level those subjects in a high stage or earnings (CI>PI) are willing to pay more for reducing accident risks. At an aggregate level this means that the VSL or VPI of a society depends not only on per capita GDP but on how many people are in a Gain scenario. This could have implications for adjustment of VSL or VPI between countries with varying income situations beyond the discussion on what exact income elasticity should be applied (see the analysis in Hammitt and Robinson, 2011, and Milligan et al., 2014). For example, imagine two countries A and B with the same level of GDP per capita. Suppose that country A is experiencing an economic crisis and as a result most of its population is in a Loss frame. On the contrary country B is on a peak of the business cycle and most of the people is in a Gain frame. If we only consider current income (measured by per capita GDP) as an explanatory variable we will predict that 
both countries have the same value of safety, i.e. $V S L^{A}=V S L^{B}$. However, given the results presented here, a better prediction would be $V S L^{A}<V S L^{B}$.

On the other hand, we estimate that, after controlling for current income, permanent income has a negative impact on safety valuation. This may be considered a psychological bias. In this case there may also be implications for correction to achieve more "normatively correct" valuations. This paternalistic approach requires the existence of normative criteria defining biased or non-rational preferences. One argument could be that if people in a high earning stage tend to pay more than those in a low earning stage we may have situations in which wealthier populations are willing to pay less than poorer societies. This is exactly what we have with countries A and B in the previous example. ${ }^{16}$ This could justify modification of WTP elicited from contingent valuation studies. ${ }^{17}$ Nonetheless, Robinson and Hammitt (2011) consider an interesting definition of a decision error: "“Mistakes" or "errors" may occur where individuals make choices that diverge from how they would define their own preferences given access to information, adequate reflection, and self-control, absent the biases that may result from cognitive or other challenges". In this sense, we cannot know whether individuals are committing mistakes in this study. For example, it could be possible that individuals do not want to change their reported WTP, even being informed of the presumed "error" and after adequate reflection.

\footnotetext{
${ }^{16}$ Notice that both countries have the same per capita GDP but people in A have a higher past or future income because its population is in a Loss frame. So country A is wealthier and, at the same time, it has the lowest VSL.

${ }^{17}$ The exact correction of elicited WTP should depend on the proposed normative criteria. Nonetheless, one way to eliminate the negative relationship between wealth and valuation of safety could be obtained by estimating a counterfactual VSL assuming that the whole population is in a Neutral frame, other variables (age, education, gender,...) being unchanged.
} 


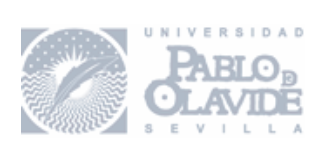

Results presented in this study are not only interesting for the safety valuation literature but in general in any field in economics or behavioral sciences aimed at studying the relationship between income, wealth and consumption decisions. Specifically, these results can be related to the literature that finds evidence that consumption is not simply a function of wealth but that the current moment within the economic life cycle is an important factor as well. For example, Karlsson et al. (1999) experimentally find that "congruent with the behavioral life-cycle theory, willingness to buy was greater when subjects received a temporary income increase than when they received a temporary income decrease although total assets were equal". Their explanation relies on behavioral life-cycle theory (Shefrin and Thaler, 1988 and 1992) that entails that propensity to consume is lower when saved money has to be used. However this explanation seems not to be valid for the income frames effect, found in the present work (see Table IV and V above), since it is estimated after controlling for current income. In principle, the three income frames ( $G, N$ and $L$ ) should have similar necessity of using saved money for consumption of road safety.

In conclusion, the relationship between wealth and monetary valuation of safety seems to be more complex than standard safety economics suggests. Theoretical accounts by Jones-Lee (1974, 1976 and 1989) are sufficient to explain the positive effect found for current income in this study and in previous works (Andersson, 2013 and 2007; Hammitt and Robinson, 2011; Lindhjem et al., 2011; Persson et al. 2001a; Jones-Lee et al. 1993 and 1985). However, according to the results here presented, the position of the permanent income with respect to the current earnings is also important suggesting a negative relationship between wealth and WTP after controlling for current income. To 

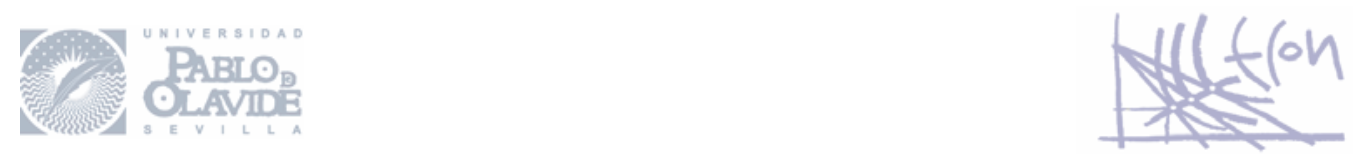

the extent of our knowledge this result has never been obtained in previous empirical or theoretical studies. Here we offer a plausible explanation based on a utility function that is affected by current income and a reference point. Permanent income would be the reference point. The rationale of this approach relies on the fact that the valuation of current income depends on the income frame. First, the present income situation is valued more by those in a Gain scenario so that they give much importance to the prevention of fatal or non fatal injuries. Second, those who are in a Gain scenario do not value that much relatively small variations in current income and are willing to give up a higher amount of money than those in a Neutral and Loss scenario. The consideration of a relative income utility is consistent with the empirical literature on subjective well being (Clark et al., 2008) and with Prospect Theory (Kahneman and Tversky, 1979; and Tversky and Kahneman, 1992). Eventually, one possible interpretation of our results is that the reference point is mainly given by past income because we find a stronger and more significant effect of the income frames for older subjects.

\section{ACKNOWLEDGEMENTS}

I want to express my gratitude to José L. Pinto-Prades, José M. Abellán-Perpiñán, William Neilson, José I. García-Pérez, Juan D. Moreno-Ternero and Patricia CubíMollá for their helpful comments and discussion. I also thank participants to a seminar at Pablo de Olavide University and participants at the 34th Spanish Health Economics 
Conference, Pamplona. The usual disclaimers apply. I thank Junta de Andalucia for its support (proyecto de excelencia código P09-SEJ-4992) and the Spanish Road Traffic Directorate General (Dirección General de Tráfico) for an unrestricted grant.

\section{REFERENCES}

1. Agencia Tributaria (2014). Informe anual de recaudación tributaria. Año 2013. http://www.agenciatributaria.es/static files/AEAT/Estudios/Estadisticas/Informes Estad 
isticos/Informes_Anuales_de_Recaudacion_Tributaria/Ejercicio_2013/IART_13.pdf (last access 20-02-2015).

2. Andersson, H. (2013). Consistency in preferences for road safety: An analysis of precautionary and stated behaviour. Research in Transportation Economics, 43: 41-49

3. Andersson, H. (2007). Willingness to pay for road safety and estimates of the risk of death: Evidence from a Swedish contingent valuation study, Accident Analysis and Prevention, 39 (4): 853-865

4. Carthy, T., Chilton, S., Covey, D., Hopkins, L., Jones-Lee, M., Loomes, G., Pidgeon, N., and Spencer, A. (1999). On the contingent valuation of safety and the safety of contingent valuation: Part 2 - the CV/SG "chained" approach. Journal of Risk and Uncertainty, 17(3): 187-213.

5. Clark, A. E. (1999). Are Wages Habit-Forming? Evidence from Micro Data. Journal of Economic Behavior and Organization, 39(2): 179-200.

6. Clark, A. E., Frijters, P., and Shields, M. (2008). Relative income, happiness and utility: An explanation for the Easterlin paradox and other puzzles. Journal of Economic Literature, 46: 95-144.

7. de Blaeij, A., Florax, R. J., Rietveld, P., and Verhoef, E. (2003). The value of statistical life in road safety: a meta-analysis. Accident Analysis \& Prevention, 35(6), 973-986.

8. Grund, C., and Sliwka, D. (2007). Reference-Dependent Preferences and the Impact of Wage Increases on Job Satisfaction: Theory and Evidence. Journal of Institutional and Theoretical Economics,163(2): 313-35.

9. Hammitt, J. K., and Robinson, L. A. (2011). The income elasticity of the value per statistical life: transferring estimates between high and low income populations. Journal of Benefit-Cost Analysis, 2(1): 1-27.

10. Instituto Nacional de Estadística (2011). Encuesta de Población Activa. Primer trimester de 2011. http://www.ine.es/daco/daco42/daco4211/epa0111.pdf (last access 20-02-2015).

11. Jones-Lee M. (1989). The economics of safety and physical risk. Oxford: Basil Blackwell.

12. Jones-Lee, M. (1976). The Value of a Statistical Life: An Economic Analysis. University of Chicago Press, Chicago.

13. Jones-Lee, M. (1974). The value of changes in the probability of death or injury. The Journal of Political Economy, 82(4): 835-849.

14. Jones-Lee, M., Hammertonan, M., Philips, P. R. (1985). The Value of Safety: Results of a National Sample Survey. The Economic Journal, 95: 49-72. 
15. Jones-Lee, M., Loomes, G., O’Reilly, D. and Philips, P. (1993). The Value of Preventing Non-fatal Road Injuries: Findings of a Willingness-to-Pay National Sample Survey. Working Paper No. WPSRC2 (Crowthorne: Transport Research Laboratory).

16. Jones-Lee, M. W., Loomes, G., and Philips, P. R. (1995). Valuing the prevention of non-fatal road injuries: Contingent valuation vs. standard gambles. Oxford Economic Papers, 676-695.

17. Kahneman, D., and Tversky, A. (1979). Prospect theory - analysis of decision under risk. Econometrica, 47(2): 263-291.

18. Karlsson, N., Gärling, T., and Selart, M. (1999). Explanations of effects of prior income changes on buying decisions. Journal of economic psychology, 20(4), 449-463.

19. Lindhjem H, Navrud S, Braathen NA, Biausque V. (2011). Valuing Mortality Risk Reductions from Environmental, Transport, and Health Policies: A Global Meta-Analysis of Stated Preference Studies. Risk analysis, 31(9): 1381-1407.

20. McBride, M. (2010). Money, happiness, and aspirations: An experimental study. Journal of Economic Behavior and Organization, 74(3): 262-276.

21. Milligan, C., Kopp, A., Dahdah, S., and Montufar, J. (2014). Value of a statistical life in road safety: A benefit-transfer function with risk-analysis guidance based on developing country data. Accident Analysis \& Prevention, 71, 236-247.

22. Persson, U., Norinder, A., Hjalte, K., Gralén, K. (2001a). The Value of a Statistical Life in Transport: Findings from a New Contingent Valuation Study in Sweden. Journal of Risk and Uncertainty, 23(2): 121-134.

23. Persson, U., Trawén, A., Norinder, A., Hjalte, K., and Andersson, H. (2001b). Relative Risk Values of Non-Fatal Traffic Injuries - A Comparison Between Contingent Valuation, Risk-Risk Trade Off and Standard Gamble Methods. Swiss Journal of Economics And Statistics, 137 (1): 117-128.

24. Robinson, A., Loomes, G., and Jones-Lee, M. (2001). Visual analog scales, standard gambles, and relative risk aversion. Medical Decision Making, 21(1): 17-27.

25. Robinson LA, Hammitt JK. Behavioral economics and the conduct of benefitcost analysis: towards principles and standards. Journal of Benefit-Cost Analysis 2011;2(2).

26. Shefrin, H. M., and Thaler, R. H. (1988). The behavioral life-cycle hypothesis. Economic Inquiry, 26, 609-643.

27. Shefrin, H. M., \& Thaler, R. H. (1992). Mental accounting, saving, and selfcontrol. In G. Loewenstein, J. Elster, Choice over time (pp. 287-330). New York: Russel Sage Foundation. 
28. Spackman, M., Evans, A., Jones-Lee, M., Loomes, G., Holder, S., Webb, H., and Sugden, R. (2011). Updating the VPF and VPIs: Phase 1: Final Report Department for Transport. London: NERA Economic Consulting.

29. Tversky, A., and Kahneman, D. (1992). Advances in prospect-theory cumulative representation of uncertainty. Journal of Risk and Uncertainty, 5(4): 297-323. 


\section{APPENDIX A. THEORETICAL MRS OF $c i$ FOR RISK OF DEATH AND}

\section{INJURY}

MRS of $c i$ for risk of death. The expected utility of a subject facing a risk of death $p$ is

$$
\overline{E U}=(1-p) U(c i, r)+p D(c i) .
$$

The Marginal Rate of Substitution (MRS) of $c i$ for risk of death is computed by deriving (A1) with respect to $p$,

$$
\frac{\partial \overline{E U}}{\partial p}=\frac{\partial[(1-p) U(c i, r)]}{\partial p}+\frac{\partial[p D(c i)]}{\partial p} .
$$

Since the individual expected utility remains constant then $\frac{\partial \overline{E U}}{\partial p}=0$, and expression (A2) would be like, $-U(c i, r)+(1-p) U_{c i}(c i, r) \frac{\partial c i}{\partial p}+D(c i)+p D^{\prime}(c i) \frac{\partial c i}{\partial p}=$ $0 ;\left[(1-p) U_{c i}(c i, r)+p D^{\prime}(c i)\right] \frac{\partial c i}{\partial p}=U(c i, r)-D(c i)$. So that the MRS is:

$$
m_{D}(c i, r)=\frac{\partial c i}{\partial p}=\frac{U(c i, r)-D(c i)}{(1-p) U_{c i}(c i, r)+p D^{\prime}(c i)}
$$

Analogously we can compute the MRS of current income for risk of injury. 


\section{APPENDIX B. NON FATAL ROAD INJURIES}

\begin{tabular}{|c|c|}
\hline $\mathbf{F}$ & $\mathbf{W}$ \\
\hline $\begin{array}{l}\text { - Does not require hospitalization, the } \\
\text { patient is treated in outpatient settings. } \\
\text { After Effects: } \\
\text { - Mild to moderate pain for } 1 \text { week. } \\
\text { - There are difficulties in work and leisure } \\
\text { activities that gradually reduce. } \\
\text { After } 3 \text { or } 4 \text { months, full recovery without } \\
\text { any sequelae. }\end{array}$ & $\begin{array}{l}\text { In hospital: } \\
\text { - } 1 \text { week } \\
\text { - } \quad \text { Mild pain } \\
\text { After Effects: } \\
\text { - } \quad \text { Pain or discomfort for several weeks. } \\
\text { - There are difficulties in work and leisure } \\
\text { - } \quad \text { activities that gradually reduce. } \\
\\
\quad \text { any sequelae. }\end{array}$ \\
\hline $\mathbf{X}$ & $\mathbf{V}$ \\
\hline $\begin{array}{l}\text { In hospital: } \\
\text { - } 2 \text { weeks } \\
\text { - } \quad \text { Moderate pain } \\
\text { After Effects: } \\
\text { - } \quad \text { Pain gradually reduces. } \\
\text { - There are difficulties in work and leisure } \\
\text { - } \quad \text { activities that gradually reduce. } \\
\text { any sequelae. }\end{array}$ & $\begin{array}{l}\text { In hospital: } \\
\text { - } 2 \text { weeks } \\
\text { - Moderate pain } \\
\text { After Effects: } \\
\text { - moderate to severe pain for 1-4 weeks } \\
\text { - Then, the pain gradually fades, but } \\
\text { reappears when performing certain } \\
\text { activities. } \\
\text { There exist permanent restrictions to } \\
\text { work and leisure activities. }\end{array}$ \\
\hline $\mathbf{S}$ & $\mathbf{R}$ \\
\hline $\begin{array}{l}\text { In hospital: } \\
\qquad \quad 4 \text { weeks } \\
\qquad \quad \text { Moderate to severe pain }\end{array}$ & $\begin{array}{l}\text { In hospital: } \\
\text { - More than } 4 \text { weeks, possibly several } \\
\text { months } \\
\text { - Moderate to severe pain }\end{array}$ \\
\hline $\begin{array}{l}\text { After Effects: } \\
\text { - moderate to severe pain for 1-4 weeks } \\
\text { - Then, the pain gradually fades, but } \\
\text { reappears when performing certain } \\
\text { activities. } \\
\text { - There exist permanent restrictions to } \\
\text { work and leisure activities. }\end{array}$ & $\begin{array}{l}\text { After Effects: } \\
\text { - Lifelong chronic pain } \\
\text { - There are major and permanent } \\
\text { restrictions to work and leisure activities. } \\
\text { - Possibly some prominent and permanent } \\
\text { scars. }\end{array}$ \\
\hline $\mathbf{N}$ & $\mathbf{L}$ \\
\hline $\begin{array}{l}\text { In hospital: } \\
\text { - More than } 4 \text { weeks, possibly several } \\
\text { months } \\
\text { - Inability to use the legs and arms, } \\
\text { possibly due to paralysis or amputation. }\end{array}$ & $\begin{array}{l}\text { In hospital: } \\
\text { - More than } 4 \text { weeks, possibly several } \\
\text { months } \\
\text { - Head injuries that cause permanent brain } \\
\text { damage }\end{array}$ \\
\hline $\begin{array}{l}\text { After Effects: } \\
\text { - Confined to a wheelchair for the rest of } \\
\text { life } \\
\text { - Dependent on others for many physical } \\
\text { needs such as dressing and toileting }\end{array}$ & $\begin{array}{l}\text { After Effects: } \\
\text { - Mental and physical abilities greatly } \\
\text { reduced for the rest of your life. } \\
\text { - Dependent on others for many physical } \\
\text { needs such as dressing and toileting }\end{array}$ \\
\hline
\end{tabular}

\section{Figure B1. Non Fatal Road Injuries (NFRIs) for valuation}

